\title{
ANALYSIS OF PSYCHOLOGICAL ASPECTS OF COLLEC- TIVE AND SOCIAL LEARNING OF CADETS OF NATIONAL GUARD OF UKRAINE
}

\author{
Larysa Morozova ${ }^{1}$ \\ ${ }^{1}$ Department of Psychology and Pedagogy, National Academy of National Guard of Ukraine, Kharkiv, Ukraine \\ lara.1962@ukr.net \\ ORCID: http://orcid.org/0000-0001-7332-8224
}

ARTICLE INFO

ABSTRACT

Article history:

Received date 08.01.2020

Accepted date 21.01 .2020

Published date 31.01.2020

The article analyzes the general features of the implementation of collective and social

Section:

Social aspects of education learning of cadets of the National Guard of Ukraine, which allowed to determine the main aspects of achieving effective indicators of learning of military personnel. A study of the main forms of social learning is done that can be used to train cadets of the National Guard of Ukraine. This allows to identify the main types of activities to imDO I prove the social learning of cadets. The main types of cadets' activities are examined

$10.21303 / 2313-8416.2020 .001152$ in the context of the main types of social learning activities. The features of the use of educational computer simulations for the learning of cadets of the National Guard of

KEYWORDS Ukraine are analyzed. The psychological conditions of storytelling for collective and social learning of cadets of the National Guard of Ukraine are studied, the accounting of which provides effective learning for the units of the National Guard of Ukraine.

National Guard of Ukraine

collective learning

social learning The main types of stories that can be used and successfully implemented in the framework of storytelling for collective and social learning of cadets of the National Guard of Ukraine are considered. Attention is focused on the need to use stories that establish a connection with the personal experience of the listener or contribute to the creation of clear visual images. These stories and vivid stories are more effective carriers of knowledge than the data given simply in the form of a list.

(C) The Author(s) 2020. This is an open access article under the CC BY license http://creativecommons.org/licenses/by/4.0).

\section{Introduction}

In the last quarter of the twentieth century, experts in the field of humanitarian knowledge noted that humanity has suffered a crisis of social and professional competence, the essence of which lies in the rapid lag of a person's ability to cope with changes in the world around the pace of these changes. A society of the 21st century, a century of informatization and great social dynamics, requires an adequate level of learning. This is due to the increased attention of all the leading countries of the world to their educational systems, their modernization in order to achieve greater efficiency. The traditional basic model of learning has been replaced by a focus on lifelong learning. In particular, in the European Union it is considered as one of the main elements of the social model.

Due to these aspects, the role of collective and social learning is increasing in the modern information society. In particular, this concerns the specifics of the learning of cadets of the National Guard of Ukraine, where the psychological factors of the educational process are greatly enhanced in the context of the future activities of graduates in military units.

In these conditions, the task of analyzing the psychological aspects of the collective and social learning of cadets of the National Guard of Ukraine is very relevant today.

\section{Literature review}

The study [1] considers specific features of the use of multimedia components in modern pedagogical technologies. In [2], a diagnostic method is proposed for assessing the quality of knowledge of learning applicant. The scientific work [3] proposes conceptual foundations 
for improving the management of labor resources based on the psychological aspects of collective and social learning. The issue of technological support for the learning information system is considered in [4]. The main criteria for assessing the effectiveness of the educational process are systematized in the study [5]. The scientific work [6] addresses the issue of the scale of the use of e-learning in European countries. In [7], hypermedia systems are proposed for collective and social learning. The scientific work [8] describes an electronic system interface model that can be used for collective and social learning of cadets. The experience of creating and functioning social learning systems in the EU is considered in [9]. The main aspects of designing an intelligent user interface for collaborative and e-learning support systems are given in the study [10].

So, as a result of the analysis of specialized literature, it is possible to conclude that there is no systematic review of the psychological aspects of collective and social learning of cadets of the National Guard of Ukraine.

\section{The aim and objectives of research}

The aim of research is a systematic analysis of the features of collective and social learning of cadets of the National Guard of Ukraine.

To achieve the goal, the following tasks were set:

- analysis of the general features of the implementation of collective and social learning of cadets of the National Guard of Ukraine;

- study of the main forms of social learning that can be used to train cadets of the National Guard of Ukraine;

- analysis of the psychological conditions of storytelling for collective and social learning of cadets of the National Guard of Ukraine.

\section{General features of the implementation of collective and social learning of cadets of the National Guard of Ukraine}

In the broadest sense, social learning means that people interact with each other in all areas of their lives and when they see how someone behaves in such a way that leads to success, they most likely begin to reproduce this behavior hoping to get the same results. An important mechanism underlying this phenomenon is that people tend to seek social approval and acceptance, which is why they copy the forms of behavior that are accepted in the society where they exist in order to receive appropriate incentives and not receive the punishments that follow for violation of social norms.

In conditions of collective and social learning, cadets of the National Guard of Ukraine should be based on the 70:20:10 model. According to it, 70\% of learning is carried out in the course of personal practical experience (at work), $20 \%$ - in the process of social experience (communication with colleagues, managers, etc.), $10 \%$ - in the course of studying courses and books.

Such learning gives the command of military units many opportunities - to create their own content and share it with contractors, to search for the necessary information, to acquire new knowledge and practice new skills, to repeat the learned, to extract implicit knowledge, etc. Sometimes this learning is called personal knowledge management or simply smart-work, because a person can use any services and platforms available to it in order to find answers to any questions, that is, learning begins at the moment when there is a need.

The main forms of social learning that can be used to train cadets of the National Guard of Ukraine are given in Table 1.

In the pedagogical practice of learning cadets of the National Guard of Ukraine, three main types of educational computer simulations can be used:

- simulations that develop a response rate;

- simulations that help develop the ability to solve professional problems;

- simulations aimed at developing the ability to evaluate and manage received information. 
Table 1

Forms of social learning

\begin{tabular}{c} 
Forms of social learning \\
\hline Timely access to learning, discussions, expert knowledge and \\
real-time support \\
Collaboration with a community of practice in social learning
\end{tabular}

Identification, collection and dissemination of best works

$$
\text { User collaboration }
$$

Possibility of real communication with the best instructors, specialists and experts

Collection of information about services, products and courses, as well as work with focus groups

A learning environment in which coaches, mentors, teachers and instructors interact, which provides an opportunity to educate those who wish and share knowledge

News dissemination

Monitoring and maintaining interaction

\section{Activity Types}

Content, Communications, Ease of Consumption

Content, usability, user input, communication, collaboration, communication, control User input

Content, usability, user input, communication, collaboration, communication, control

Communications

Collaboration, communication

Content, usability, user input, communications, collaboration, communication, control

Communication

Content, usability, user input, communications, collaboration, communication, control

\section{Research results and their discussion}

In the psychological practice of collective and social learning of cadets of the National Guard of Ukraine, storytelling occupies an important place, which means informal stories about specific objects or subjects, people informally tell and spread on social networks. Such stories, as a rule, have a plot, main characters and denouement. The moral of the story or conclusion, as a rule, is meant, but can be expressed openly. Typically, these stories come from the depths of the organization and therefore reflect its norms, values and culture. However, mentors outside the unit use stories from the past to emphasize key skills, management systems, norms and values common to all organizations.

There are seven types of stories that are characteristic of a wide variety of organizations, including military ones:

- Story of non-compliance with the rules.

- How human is the boss?

- Can a person rise from the bottom to the very top?

- Will not fire me?

- Will the organization support me if I have to move?

- How does management respond to errors?

- How does an organization overcome obstacles?

The most important aspects of social learning and collective learning are not so much specific pedagogical and psychological technologies and tools, but rather the means that people receive to interact and exchange knowledge. The bottom line is that at exactly the moment when a vague question arises, it is possible to turn to other people - both inside the unit or organization, and outside them - and get the necessary answer. Perhaps a colleague sitting with it in the same office can help a person, maybe an expert who also works in the organization, but is not at all familiar with our employee. And perhaps the answer can be obtained simply from someone who works with a worker in one industry, but in a completely different company, but at the same time these two people are friends on a social network. There may be many options. The main thing is that the employee should be able to reach all these people and solve its problem as soon as possible. The organization's task is precisely to provide these opportunities, and possibly to show how they can be used.

In the context of the learning of cadets of the National Guard of Ukraine, information is more likely to be used, remembered, than that which remains unconscious and is not extracted from memory. Therefore, everything that usually makes information more memorable is more likely to give meaning to it. Since stories are more expressive, exciting, interesting, and easier associated with personal experience than rules or directives, they are better remembered, they are given more importance and their influence on people's behavior is stronger. In addition, stories, due to the rich 
set of context details, usually in them, are ideal carriers of implicit aspects of knowledge (although what the listener usually "encodes" for itself may not be related to the narrator's intentions).

Different types of knowledge require different stories to convey. It is wrong, without hesitation, to use any stories when transferring the most important skills, management systems, norms and values as a strategy for creating key abilities in an organization. Critical skills, including a deep knowledge of the subject area, are quite difficult to convey through storytelling. To rely on such specific forms of knowledge, people rely on formal learning, apprenticeships or mentoring, and learning and self-study programs.

Management systems, norms and values can be easily conveyed through the story and its (often seeming) morality. For the transfer of knowledge saturated with implicit aspects, specific stories are especially useful with which it is not difficult for students to relate their own experience. As already mentioned, the transfer of knowledge about skills and subject areas relies more on explicit, formalized means of communication, rather than storytelling.

One story with a rich context can convey knowledge, often implicit, about several key unit capabilities at once. For example, a story like "How does a unit overcome obstacles?" narrates that employees who present the results of their work to management may encounter harsh criticism, accompanied by screams, humiliation, and scattering of their papers. While at the explicit level, this story may not be unflatteringly evaluating specific organizational values or management systems, the hidden moral is that leadership is worried about quality and a career depends on the success of such a "dedication".

When a story supports the unit's explicit values (as is usually the case), it serves as a powerful reinforcement and draws the attention of employees. If it contradicts them, then its implicit morality can negate an explicit message. Moreover, negative and positive examples can be found for each of the seven types of stories.

So, if the stories help the development process, for example, establish a connection with the personal experience of the listener, or create clear visual images, they will be better remembered and therefore will become more effective knowledge carriers than the data given simply in the form of a list. It is especially important that vivid stories will be more likely to be perceived as true or possible.

\section{Conclusions}

1. The analysis of the general features of the implementation of collective and social learning of cadets of the National Guard of Ukraine, which allow to determine the main aspects of achieving effective performance learning of military personnel.

2. A study of the main forms of social learning that can be used to train cadets of the National Guard of Ukraine. This allows to identify the main types of activities to improve the social learning of cadets.

3. The psychological conditions of storytelling for collective and social learning of cadets of the National Guard of Ukraine, the accounting of which provides effective learning for the units of the National Guard of Ukraine, are investigated.

\section{References}

[1] Hrabovskyi, Y. (2019). Analysis of the use of multimedia components in modern mobile learning technologies. ScienceRise, 4 (57), 46-50. doi: http://doi.org/10.15587/2313-8416.2019.164597

[2] Hrabovskyi, Y. (2015). Methods of Assessment and Diagnosis of the Quality of Knowledge in E-Learning. Journal of Communication and Computer, 12 (6), 286-296. doi: http://doi.org/10.17265/1548-7709/2015.06.002

[3] Sokolovskyi, S. A., Naumenko, M. O., Cherkashyna, M. V. (2015). Udoskonalennia upravlinnia trudovymy resursamy pidpryiemstva. Biznes Inform, 3, 288-292.

[4] Kitchenham, A. (2011). Blended learning across disciplines: Models for implementation. Hershey: Information Science Reference (an imprint of IGI Global), 278. doi: http://doi.org/10.4018/978-1-60960-479-0

[5] Singh, H. (2003). Building Effective Blended Learning Programs. Issue of Educational Technology, 43 (6), 51-54.

[6] Bichel, J. (2013). The state of e-learning in higher learning: An eye toward growth and increased access (research report). Louisville: EDUCAUSE, 46.

[7] Karampiperis, P. (2005). Adaptive Learning Resources Sequencing in Educational Hypermedia Systems. Educational Technology \& Society, 8 (4), 128-147.

[8] Hrabovskyi, Y., Fedorchenko, V. (2019). Development of the optimization model of the interface of multimedia edition. Eureka: Physics and Engineering, 3, 3-12. doi: http://doi.org/10.21303/2461-4262.2019.00902

[9] Sursock, A. (2015). Trends 2015: Learning and Teaching in European Universities. Brussels: EUA, 128.

[10] Hrabovskyi, Y. (2018). Designing the intelligent user interface for electronic learning support systems. ScienceRise, 11 (52), 36-39.. doi: http://doi.org/10.15587/2313-8416.2018.147987 